IJBPAS, March, 2022, 11(3): 1513-1524

ISSN: $2277-4998$

International Journal of Biology, Pharmacy and Allied Sciences (IJBPAS)

'A Bridge Betuben Cabratory and QRader'

WwW.ijbpas.com

\title{
A STUDY ON ASSESSMENT OF DISPENSING PATTERN OF OVER THE COUNTER DRUGS IN COMMUNITY PHARMACY PRACTICE
}

\author{
NISAR AHMED ${ }^{1 *}$, PARIMALAKRISHNAN S ${ }^{2}$ AND BHAGAT MP ${ }^{3}$ \\ 1: Associate Professor, Department of Pharmacy Practice, Farooqia College of Pharmacy, Mysore \\ 2: Associate Professor, Department of Pharmacy, Annamalai University, Annamalai Nagar 608002
}

3: Professor, Pharmaceutical Chemistry Department, Farooqia College of Pharmacy, Mysore

*Corresponding Author: Dr. Nisar Ahmed: Email: nisarpharma75@gmail.com

Received 26 ${ }^{\text {th }}$ April 2021; Revised 24 ${ }^{\text {th }}$ May 2021; Accepted $30^{\text {th }}$ June 2021; Available online $1^{\text {st }}$ March 2022

https://doi.org/10.31032/IJBPAS/2022/11.3.6246

\begin{abstract}
Background:

OTC medicines refers to medicines can be sold without a prescription. The prescribing pattern of essential medicines save the lives and enhance the health of the individuals and prevent the critical situation of health care demands. Aim: A study aimed to assess dispensing pattern of over the counter drugs in community pharmacy practice. Methods: A prospective observational study was conducted in community pharmacies of Mysore city. Karnataka. The study was conducted from January 2020 to July 2020. A sample size of 170 participants was enrolled in the study. The collected data was analyzed and expressed in percentages. Results and Discussion: In our study 25-35 age customers were more $125(73.52 \%)$ as compared to other ages. The male customers were more $143(84.11 \%)$ as compared to female customers 27 (15.88\%). Retail pharmacies were more $122(71.76 \%)$ as compared to other pharmacies. 3-4 OTC medications received customers were more $86(50.58 \%)$ as compared to other customers. Antitussives and expectorants OTC prescriptions were more 34 (20\%) as compared to other OTC medications. Conclusion: The study concludes that the prevalence of over the counter medication practice is
\end{abstract}


very high in India. There is a need for strict drug guidelines and upholding dispensary regulations and enforcement of standard prescription-based dispensaries can helpful for reduction of OTC practice in community settings.

Keywords: OTC medications, health care demands, community pharmacy practice, prescription INTRODUCTION

The more usage of 'Over-the-Counter (OTC) Medicines' use has been steadily increasing in the last few years. The prescribing of OTC medications is linked with many clinical reasons which include easy availability, and peoples were aware about OTC practices. OTC medicines refers to medicines can be sold without a prescription. Many countries have different medications regulating rules and regulations for medications utilization. In India there are no proper guidelines for licensing of OTC medicines. Still in India no separate category is allotted for OTC medicines and the drugs which do not come under the prescription medicines sold as over-the-counter medicines. The prescribing pattern of essential medicines save the lives and enhance the health of the individuals and prevent the critical situation of health care demands. The utilization of medicines is the fundamental right of every person. The cost effectiveness of the medications promotes rationality in prescription. Medications are an integral part of the health care and modern health care it is not possible to get availability of essential medications. Drug utilization is defined by world health organization is marketing, distribution, and use of drugs in society which results in social and economical consequences of the society [1-3]. The Pharmacoepidemiology studies are done in more number of people to promote the rational use of medications therefore to enhance the health outcomes of patient. Drug utilization research is an essential part of pharmacoepidemiology that describes the determinants of drug exposure. Prescription pattern monitoring studies describes dispensing and administering of drugs. It promotes appropriate use of medications and lowers the medication misuse practice. Prescription pattern studies support prescribers, and the general public on appropriate use of drugs to collaborate with other health care workers to achieve a rational use of drugs. Prescription patterns explain the extent and profile of drug use trends and must compliance with standard treatment guidelines, usage of drugs from essential medicine list and use of generic drugs. At present there is an increasing demand for Prescription patterns because of a 
boost in marketing of new drugs, and variations in pattern of prescribing and consumption of drugs in hospitals. It promotes appropriate use of prescription drugs and reduces medication abuse. The use of OTC medications has been rising internationally [4-6]. The OTC drug market in India currently ranks 11th in the global OTC market and it is expected to reach 9th position within next 5 years. The Indian population have tendency of self treatment so the Indian market of huge demand for OTC drugs. In India OTC has no legal recognition and all the drugs are not included in the list of prescription drugs. Prescription drugs deals with schedule $\mathrm{H}$ and schedule $\mathrm{X}$. Schedule $H$ and $X$ are drugs can be sold only on the prescription of a registered medical practitioner [7-9]. The strict legal requirement is required to prevent self medication of drugs. Consumers approaching to community pharmacies depend more on community pharmacists due to expediency, shorter waiting time, cost reduction, availability of credit and convenient opening hours. Poor education qualification of community pharmacist and lack of professional development programmes are responsible for leading medication related problems in health care. Commonly customers approach community pharmacists for purchasing self medications where antibiotics are dispensed by community pharmacist tend to cause antibiotic resistance. More consumption of antihistamines, tramadol and morphine may be responsible for drug habituation and addiction. American Pharmaceutical Association recommended that dispensing of prescription products to OTC products only under the supervision of legally qualified pharmacists [10-11]. The individuals can buy medicines without prescription of doctors. The over the counter practice we can observe in community pharmacy settings and the tern OTC is used to describe the medications. The benefits of the over the counter medicines are more convenient and easy of access which helps to enhance the patient's health condition. Each medication has certain limitations and indication, uses, clinical applications. The misuse of OTC medications causes drug addiction and drug dependency. The commonly prescribed OTC medications include stimulants, laxatives, sedatives and dissociative substances such as dextromethorphan. OTC drugs are repeatedly purchased by the patients without clinician prescription has less safe and used to treat the specific conditions. These are classified according to the world health organization anatomical therapeutic Chemical (ATC) 
classification in ten categories that includes analgesics, laxatives, antithrombotic agents, antacids, cough and cold preparations, antihistamines, dermatologicals, throat preparations, nasal preparations and antidiarrheals. A self medication practice lowers the progression of chronic diseases and minor ailment of diseases. Inappropriate use of OTC drugs leads to serious implications in pregnant and pediatrics and geriatrics, and patients with several comorbidities that finally cause death of patients. In developing countries the pharmacy shops dispense medications by prescription only and non prescription medications are not prescribed [12-14]. The availability of OTC medications is easy in the pharmacies as compared to the prescribed medications. Currently there is a lack of drug regulation policies is the major reason for OTC practice in the community settings. Irrational use of antibiotics causes antibiotic resistance in the community. The availability of non prescription medications may support the patient to think that OTC drug treatment available for every element. Over-TheCounter drugs are the essential self medications that have been used in the treatment for health related sickness. The OTC practice provides more advantages to patients, general practitioners, pharmacists, pharmaceutical companies and the government. Patients can benefit from effective therapy to treat complex ailments without clinician intervention [15-18]. The worldwide increase of more health cost increased in males and females. OTC drugs are low price and relatively safe, and shows harmful effects on the human body. The community pharmacists are the health care professionals help to patients, customers and to ensure safe prescribing of medications in community care.

\section{AIM}

A study aimed to assess dispensing pattern of over the counter drugs in community pharmacy practice.

\section{OBJECTIVES}

1) To assess the prescription patterns of OTC medications

2) To evaluate the disease conditions associated with use of OTC medications

3) To analyze the medication combinations with the use of OTC medications

\section{METHODOLOGY}

A prospective observational study was conducted in community pharmacies of Mysore city. Karnataka. The study was conducted from January 2020 to July 2020. The study was done in accordance with the 
declaration of helsinki and institutional standards. The customers who are purchasing medicines without a physician prescription were included in the study. Patients buying the medicines other than allopathic drugs and not willing to participate in study were excluded from the study. The study data was collected by interview, direct personnel interaction with study patients. A sample size of 170 participants was participated in the study. Daily we have visited the community pharmacies for a period of six months by the study investigator to observe the usage pattern of OTC medications were sold in community pharmacies. The demographic details of the patients including name and details of prescription medications details were collected.

\section{Ethical considerations:}

The study protocol was approved by the human ethics committee.

\section{Ethical approval number: FCP/IEC/1318/2017}

\section{Questionnaire design:}

Patients were interviewed by the investigator using a structured questionnaire between $6 \mathrm{pm}-9 \mathrm{pm}$ in the respective pharmacies. The questionnaire contains demographic details, patient complaints, instructions by the pharmacists, awareness about the adverse effects, and contraindications of the dispensed drugs. Data was analyzed by descriptive statistics using Microsoft Excel. A questionnaire was designed by study investigator. The study patients were interviewed by investigator using a self designed questionnaire. The number of questions was made short to avoid ambiguity. At the initial research questionnaire was administered to few patients and checked for content validity, reliability, the questions were modified. The questionnaire was validated by professional experts.

\section{Statistical analysis:}

The collected data was analyzed using Microsoft Excel sheet, and descriptive statistics was done by SPSS version 20. The results were expressed by mentioning in percentage distribution in various categories. A statistical significance of $\mathrm{p}<0.05$ was found in this study.

\section{RESULTS}

In our study 25-35 age customers were 125 (73.52\%), 36-45 age customers were 22 (12.94\%), 46-55 age customers were 23 (13.52\%) (Table 1).

The male customers were $143(84.11 \%)$ and female customers were 27 (15.88\%) (Table 2). Retail pharmacies were 122 (71.76\%), chain pharmacies were 45 (26.47\%) and own pharmacies were $3(1.76 \%)$ (Table 3). 
Primary school education customers were 121 (71.17\%), secondary school education customers were $40(23.52 \%)$ and degree qualification customers were 9 (5.29\%)

\section{(Table 4).}

The Number of OTC medications received customers include 1-2 OTC medications received customers were 57 (33.52\%), 3-4 OTC medications received customers were 86 (50.58\%), 5-6 OTC medications received customers were 27 (15.58\%) (Table 5).

Marital status include married 88 (51.76\%), single 62 (36.47\%), Widow 12 (7.05\%), and divorced 8 (4.70) (Table 6).

Smoking habitual participants were 97(57.05\%), and alcohol subjects were 73 (42.94\%) (Table 7).

Labour occupation were 56 (32.94\%), Business 62 (36.47\%), Student 22(12.94\%), 18 (10.58) (Table 8).

Diabetes mellitus 55(32.55\%), hypertension 35 (20.58\%), heart failure 19 (11.17\%), heart failure 5 (2.94\%), Menopausal disorders 41 (24.11\%), pulmonary infection patients were 15 (8.82\%) (Table 9).

Aceclofenac + Paracetamol 29 (17.05\%),

Diclofenac + Paracetamol 64 (37.64\%), Telmisartan $+\quad$ Hydrochlorthiazide 12 (7.05\%), Omeprazole + Domperidone 18 (10.58\%), Chlorepheniramine maleate + Paracetamol 30 (17.64\%), Voglibose +
Metformin received participants were 17 (10\%) (Table 10).

The past medical history of study participants include insulin medical history participants were 45(26.74\%), amlodipine consuming participants were 33 (19.41\%), metformin consuming participants were $20(11.76 \%)$, Glimepiride consuming participants were 19(27.14\%), Montelukast consuming participants were 23 (13.52\%), Carbimazole consuming participants were $18(10.58 \%)$, Telmisartan consuming participants were 12 (7.05\%) (Table 11). Antihistamines 12 (7.05\%), NSAID received participants were 19 (11.17\%), Skeletal muscle relaxants received participants were $8 \quad(4.07 \%)$, antacids 22 (12.04\%), Anti tussives and expectorants $34(20 \%)$, laxatives $17(10 \%)$, anti spasmodics 9 (5.29\%), anti emetics 12 (7.05\%), multi vitamins received participants were 37 (21.76\%) (Table 12).

Amoxicillin was prescribed to $45(26.47 \%)$ participants, Azithromycin was prescribed to 33 (19.41\%) participants, Ciprofloxacin was prescribed to 39 (22.94\%) participants, Levofloxacin was prescribed to 23 (13.52\%) participants, metronidazole was prescribed to $18(10.58 \%)$ participants, Doxycycline was prescribed to 12 (7.05\%) participants (Table 13). 
Table 1: Age wise distribution

\begin{tabular}{|c|c|c|c|}
\hline S. No. & Age & Total N=170 & Percentage (\%) \\
\hline 1. & $25-35$ & 125 & 73.52 \\
\hline 2. & $36-45$ & 22 & 12.94 \\
\hline 3. & $46-55$ & 23 & 13.52 \\
\hline
\end{tabular}

\begin{tabular}{|c|c|c|c|}
\multicolumn{5}{|c|}{ Table 2: Gender } & Percentage (\%) \\
\hline S. No. & Gender & Total N=170 & $\mathbf{8 4 . 1 1}$ \\
\hline 1 & Male & 143 & 15.88 \\
\hline 2 & Female & 27 & \\
\hline
\end{tabular}

Table 3: Type of pharmacy

\begin{tabular}{|c|c|c|c|}
\hline S. No. & Type of pharmacy & Total N=170 & Percentage (\%) \\
\hline 1 & Retail Pharmacy & 122 & 71.76 \\
\hline 2 & Chain Pharmacy & 45 & 26.47 \\
\hline 3 & Own Pharmacy & 3 & 1.76 \\
\hline
\end{tabular}

Table 4: Educational status

\begin{tabular}{|c|c|c|c|}
\hline S. No. & Educational status & Total N=170 & Percentage (\%) \\
\hline 1 & Primary & 121 & 71.17 \\
\hline 2 & Secondary School & 40 & 23.52 \\
\hline 3 & Degree & 9 & 5.29 \\
\hline
\end{tabular}

Table 5: Number of OTC medications received by patients:

\begin{tabular}{|c|c|c|c|}
\hline S. No. & $\begin{array}{c}\text { Number of OTC } \\
\text { medications }\end{array}$ & Total N=170 & Percentage (\%) \\
\hline 1 & $1-2$ & 57 & 33.52 \\
\hline 2 & $3-4$ & 86 & 50.58 \\
\hline 3 & $5-6$ & 27 & 15.58 \\
\hline
\end{tabular}

Table 6: Marital status:

\begin{tabular}{|c|c|c|c|}
\hline S. No. & Marital status & Total N=170 & Percentage (\%) \\
\hline 1 & Married & $\mathbf{8 8}$ & $\mathbf{5 1 . 7 6}$ \\
\hline 2 & Single & 62 & $\mathbf{3 6 . 4 7}$ \\
\hline 3 & Widow & 12 & 7.05 \\
\hline 4 & Divorced & 8 & 4.70 \\
\hline
\end{tabular}

Table 7: Social habits:

\begin{tabular}{|c|c|c|c|}
\hline S. No. & Social habits & Total $\mathbf{N}=170$ & Percentage (\%) \\
\hline 1 & Smoking & 97 & 57.05 \\
\hline 2 & Alcohol & 73 & 42.94 \\
\hline
\end{tabular}

\begin{tabular}{|c|c|c|c|}
\hline \multicolumn{5}{|c|}{ Table 8: Occupation: } \\
\hline S. No. & Occupation & Total N=170 & Percentage (\%) \\
\hline 1 & Labour & 56 & 32.94 \\
& & & 36.47 \\
\hline 2 & Business & 62 & 12.94 \\
\hline 3 & Student & 22 & 10.58 \\
\hline 4 & Agriculture & 18 & 7.05 \\
\hline 5 & Housewife & 12 & \\
\hline
\end{tabular}

Table 9 : Most frequently diagnosed chronic diseases in participants:

\begin{tabular}{|c|c|c|c|}
\hline S. No. & Diagnosis & Total N=170 & Percentage (\%) \\
\hline 1 & Diabetes mellitus & 55 & 32.35 \\
\hline 2 & Hypertension & 35 & 20.58 \\
\hline 3 & Heart failure & 19 & 11.17 \\
\hline 4 & Menopausal disorders & 5 & 2.94 \\
\hline 5 & Gastroesophageal reflux disease & 41 & $\mathbf{2 4 . 1 1}$ \\
\hline 7 & Pulmonary infections & 15 & $\mathbf{8 . 8 2}$ \\
\hline
\end{tabular}


Table 10: Percentage of fixed dose combinations:

\begin{tabular}{|c|c|c|c|}
\hline S. No. & Type of pharmacy & Total N=170 & Percentage (\%) \\
\hline 1 & Aceclofenac + Paracetamol & 29 & 17.05 \\
\hline 2 & Diclofenac + Paracetamol & 64 & 37.64 \\
\hline 3 & Telmisartan+ Hydrochlorthiazide & 12 & $\mathbf{7 . 0 5}$ \\
\hline 4 & Omeprazole + Domperidone & 18 & 10.58 \\
\hline 5 & Chlorepheniramine maleate + Paracetamol & 30 & 17.64 \\
\hline 6 & Voglibose + Metformin & 17 & 10 \\
\end{tabular}

Table 11: Past medication history of study participants

\begin{tabular}{|c|c|c|c|}
\hline S. No. & Past medication history & Total N=170 & Percentage (\%) \\
\hline 1 & Insulin & 45 & $\mathbf{2 6 . 7 4}$ \\
\hline 2 & Amlodipine & 33 & 19.41 \\
\hline 3 & Metformin & 20 & 11.76 \\
\hline 4 & Glimepiride & 19 & 27.14 \\
\hline 5 & Montelukast & 23 & 13.52 \\
\hline 6 & Carbimazole & 18 & 10.58 \\
\hline 7 & Telmisartan & 12 & 7.05 \\
\hline
\end{tabular}

Table 12: Participants' OTC medication use patterns:

\begin{tabular}{|c|c|c|c|}
\hline S. No. & Type of pharmacy & Total N=170 & Percentage (\%) \\
\hline 1 & Antihistamines & 12 & 7.05 \\
\hline 2 & NSAID & 19 & 11.17 \\
\hline 3 & Skeletal muscle relaxants & 8 & 4.07 \\
\hline 4 & Antacids & 22 & 12.94 \\
\hline 5 & Antitussives and expectorants & 34 & 20 \\
\hline 6 & Laxatives & 17 & 10 \\
\hline 7 & Antispasmodics & 9 & 5.29 \\
\hline 8 & Antiemetics & 12 & 7.05 \\
\hline 9 & Multivitamins & 37 & 21.76 \\
\hline
\end{tabular}

Table 13: Prescribing pattern of Antibiotics for various clinical conditions

\begin{tabular}{|c|c|c|c|c|}
\hline S. No. & clinical conditions & Past medication history & Total N=170 & Percentage (\%) \\
\hline \multirow{2}{*}{1} & Sore throat & Amoxicillin & 45 & 26.47 \\
\cline { 3 - 5 } & & Azithromycin & 33 & 19.41 \\
\hline \multirow{2}{*}{2} & \multirow{2}{*}{ Diarrhea } & Ciprofloxacin & 39 & 22.94 \\
\cline { 3 - 5 } & & Levofloxacin & 23 & 13.52 \\
\cline { 2 - 5 } & & Metronidazole & 18 & 10.58 \\
\hline 3 & Malaria & Doxycycline & 1.05 \\
\hline
\end{tabular}

\section{DISCUSSION}

In our study 25-35 age customers were more $125(73.52 \%)$ as compared to other ages. The male customers were more $143(84.11 \%)$ as compared to female customers 27 (15.88\%). Retail pharmacies were more 122 (71.76\%) as compared to other pharmacies. Primary school education customers were 121 $(71.17 \%)$ as compared to other educational qualification participants. 3-4 OTC medications received customers were more $86(50.58 \%)$ as compared to other customers [19-21]. Married customers were more 88 $(51.76 \%)$ as compared to other customers. Smoking habitual participants were 97(57.05\%) more as compared to alcohol habitual. Business occupation participants were more $62(36.47 \%)$ as compared to other 
occupations. Diabetes mellitus diagnosis cases were more 55(32.55\%) as compared to other diagnosis cases. Diclofenac + Paracetamol fixed dose combinations were more $64(37.64 \%)$ as compared to other fixed dose combinations. Amlodipine consuming participants were more $33(19.41 \%)$ as compared to other medical history details of participants [22-25]. Antitussives and expectorants OTC prescriptions were more $34(20 \%)$ as compared to other OTC medications. Amoxicillin was prescribed participants were more $45(26.47 \%)$ as compared to other antibiotics.

\section{CONCLUSION}

The study concludes that the prevalence of over the counter medication practice is very high in India. There is a need for strict drug guidelines and upholding dispensary regulations and enforcement of standard prescription-based dispensaries can helpful for reduction of OTC practice in community settings. Continuous public education and providing training programs for pharmacy staff to promote the appropriate use of antibiotics and to minimize the prescribing pattern of OTC medications [26-27]. The pharmacist must have good knowledge about safe use of medications, where we can create more awareness to the public about safe use of medications. Drug control and regulatory authorities in India must and should enforce strict drug policies in native states so that practicing community pharmacists should only dispense safe medications as OTC drugs. Community Pharmacists have continuous trained and educated regarding rationale dispensing of medications.

\section{AUTHORS}

CONTRIBUTION

\section{STATEMENT}

Nisar Ahmed designed the work, drafted, collected data, analyzed and interpreted the data.

Parimalakrishnan S analyzed, editing and interpreted the data. Bhagat MP revised and approved the manuscript.

\section{CONFLICT OF INTEREST: Nil}

\section{REFERENCES}

[1] Shroti R, Nayak N, Mithun Singh Rajput. A study on over the counter drugs in retail pharmacies in Indore city. Der Pharmacies Lettre. 2011; 3(3): 133-38.

[2] Hayashi M, Masuda S, Kimura H. Key information providers, channels, and characteristics of Japanese consumers' informed choices of overthe-counter medications. Springerplus. 2015; 4: 737.

[3] Aoyama I, Koyama S, Hibino H. Self-medication behaviors among Japanese consumers: sex, age, and 
SES differences and caregivers' attitudes toward their children's health management. Asia Pac Fam Med. 2012; 11(1): 7 .

[4] Eichenberg C, Auersperg F, Rusch BD, Brähler E. Self-Medication: A Nationwide Representative Survey on Motives, Reasons and Sources on Consuming Over-the-Counter Medication. Psychother Psychosom Med Psychol. 2015; 65(8): 304-310.

[5] Jensen JF, Gottshaw M, Siersma VD. Association of maternal self medication and over the counter Analgesics for children. Paediatrics. 2014; 133(2): 291-98.

[6] Bertoldi AD, Camargo AC, Silveira MP, Menezes AM, Asscencao MC, Goncalves $\mathrm{H}$, et al. Self medication among adolescents aged 18 years: the 1993 pelotas (Brazil) Birth cohort study. J Adolesc Health. 2014; 55(2): 175-81.

[7] Calamusa A, di Marzio A, Cristofani $\mathrm{R}$, et al. Factors that influence Italian consumers' understanding of overthe-counter medicines and risk perception. Patient Educ Couns. 2012; 87(3): 395-401.

[8] Raynor DK, Blenkinsopp A, Knapp $\mathrm{P}$, et al. A systematic review of quantitative and qualitative research on the role and effectiveness of written information available to patients about individual medicines. Health Technol Assess. 2007; 11(5): $1-160$.

[9] Aruna D, Naidu MU. Pharmacodynamic interaction studies of Ginkgo biloba with cilostazol and clopidogrel in healthy human subjects. Br J Clin Pharmacol. 2007; 63(3): 333-338.

[10] Akram G. Over-the-counter medication: an emerging and neglected drug abuse? J Substance Use 2000; 5: 136-142.

[11] MacFadyen L, Eadie D, McGowan T. Community pharmacists' experience of over-the-counter medicine misuse in Scotland. J R Soc Prom Health 2001; 121: 185192.

[12] 13 Erwin J, Britten N, Jones R. General practitioners' views on over the counter sales by community pharmacists. Br Med J 1996; 312: 617-618.

[13] Nightingale SL. New easy-tounderstand labels for OTC drugs. J Am Med Assoc 1999; 281: 113. 
[14] Sanz F, Silveira C, Diaz C, Alonso A, Loza M, Cordero L et al. Information Technology in community pharmacies for supporting responsible selfmedication. Am J Health Syst Pharm 2000; 57: 1601-1603.

[15] Alić A, Pranjić N, Ramić E. Polypharmacy and decreased cognitive abilities in elderly patients. Med Arh. 2011; 65(2): 102-105.

[16] De-Almeida-Neto AC, Benrimoj SJ, Gomel M, Fois R. Inappropriate self-medication practices: pharmacy-based intervention. J Soc Admin Pharm 1996; 13: 131-138.

[17] Paxton R, Chapple P. Misuse of over-the-counter medicines: a survey in one English County. Pharm J 1996; 256: 313-315.

[18] Zaghloul AA, Elsergany M, ElEnein NA, Alsuwaidi H, Ayoub M. Over-the-counter medication patterns in households in Sharjah, United Arab Emirates. Risk Manag Healthc Policy. 2013; 7: 19-24..

[19] Glick R, Hoying J, Cerullo 1, Perlman S. Phenylephrine: an over the counter drug causing central nervous system vasculitis and intracerebral

haemorrhage.

Neurosurgery. 1987; 20(6): 969-74.

[20] Gazibara T, Nurkovic S, KisicTepavcevic D, kurtagic I, kovacevic N. Pharmacotherapy and over the counter drug use among elderly in Belgrade, Serbia. Geriatr Neurs. 2013; 34(6): 486-90.

[21] Nga do TT, Chuc NT, Hoa NP, Nguyen NT, Loan HT, Toan TK, et al. Antibiotic sales in rural and urban pharmacies in northern Vietnman: an observational study. BMC Pharmacol Toxicol. 2014; 15(1): 6 .

[22] Bentosch EG, Koester S, Martin AM. Intentional misuse of over the counter medication, mental Health and Polysubstance use in young adults. J community Health. 2014; 39(4): 688-95.

[23] Martin DK. Health outcomes associated with polypharmacy in community-dwelling older adults: a systematic review. J Am Geriatr Soc. 2014; 62(12): 2261-2272.

[24] Frazier SC. Health outcomes and polypharmacy in elderly individuals: an integrated literature review. J Gerontol Nurs. 2005; 31(9): 4-11. 
[25] Veehof LJ, Stewart RE, Meyboomde Jong B, Haaijer-Ruskamp FM. Adverse drug reactions and polypharmacy in the elderly in general practice. Eur J Clin Pharmacol. 1999; 55(7): 533-536.

[26] Trumic E, Pranjic N, Begic L, Bečić F. Prevalence of polypharmacy and drug interaction among hospitalized patients: opportunities and responsibilities in pharmaceutical care. Mater Sociomed. 2012; 24(2): 6872.

[27] Abasaeed AE, Abuelkhair MA, Andrajati R, Elnour AA. A comparative study between prescribed and over the counter antibiotics. Saud Med J. 2013; 34(10): 1048-54. 